\title{
Experimental verification of a wireless sensing and control system for structural control using MR dampers
}

\author{
Chin-Hsiung Loh ${ }^{1, *, \dagger}$, Jerome P. Lynch ${ }^{2}$, Kung-Chun $\mathrm{Lu}^{1}$, Yang Wang ${ }^{3}$, \\ Chia-Ming Chang ${ }^{1}$, Pei-Yang Lin ${ }^{4}$ and Ting-Hei Yeh ${ }^{1}$ \\ ${ }^{1}$ Department of Civil Engineering, National Taiwan University, Taipei 106-17, Taiwan \\ ${ }^{2}$ Department of Civil and Environmental Engineering, University of Michigan, Ann Arbor, MI, U.S.A. \\ ${ }^{3}$ Department of Civil and Environmental Engineering, Stanford University, Stanford, CA, U.S.A. \\ ${ }^{4}$ National Center for Research on Earthquake Engineering, Taipei, Taiwan
}

\begin{abstract}
SUMMARY
The performance aspects of a wireless 'active' sensor, including the reliability of the wireless communication channel for real-time data delivery and its application to feedback structural control, are explored in this study. First, the control of magnetorheological (MR) dampers using wireless sensors is examined. Second, the application of the MR-damper to actively control a half-scale three-storey steel building excited at its base by shaking table is studied using a wireless control system assembled from wireless active sensors. With an MR damper installed on each floor (three dampers total), structural responses during seismic excitation are measured by the system's wireless active sensors and wirelessly communicated to each other; upon receipt of response data, the wireless sensor interfaced to each MR damper calculates a desired control action using an LQG controller implemented in the wireless sensor's computational core. In this system, the wireless active sensor is responsible for the reception of response data, determination of optimal control forces, and the issuing of command signals to the MR damper. Various control solutions are formulated in this study and embedded in the wireless control system including centralized and decentralized control algorithms. Copyright (C) 2007 John Wiley \& Sons, Ltd.
\end{abstract}

Received 17 January 2007; Accepted 17 January 2007

KEY WORDS: wireless active sensor; LQG control algorithm; MR-damper; decentralized control

\footnotetext{
*Correspondence to: Chin-Hsiung Loh, Department of Civil Engineering, National Taiwan University, Taipei 106-17, Taiwan.

${ }^{\dagger}$ E-mail: lohc0220@ccms.ntu.edu.tw

Contract/grant sponsor: National Science Council; contract/grant numbers: NSC 94-2625-Z-002-031, NSC 95-2221E-002-311

Contract/grant sponsor: National Science Foundation; contract/grant number: CMS-0528867

Contract/grant sponsor: Office of Naval Research
} 


\section{INTRODUCTION}

For the installation of semi-active control devices (magnetorheological (MR) dampers) in structures, extensive lengths of wires are often needed to connect sensors (to provide real-time state feedback) with a controller where control forces are calculated. In contrast to this classical approach, wireless sensors can be considered for controlling structures. In order to reduce the monetary and time expenses associated with the installation of wire-based systems, the emergence of new embedded system and wireless communication technologies have been adopted in academia and industry for wireless monitoring. The use of wireless communications within a structural health monitoring (SHM) data acquisition system was illustrated by Straser and Kiremidjian [1]. More recently, Lynch et al. have extended upon this work by embedding damage identification algorithms into the wireless sensors [2] and have proven the reliability of the system in harsh field conditions [3-5]. While the advantages of using wireless sensors for SHM have been verified in the structural monitoring area, many challenges must still be explored in greater detail before they can be adopted for structural control.

To dissipate hysteretic energy and to indirectly apply control forces to a civil structure, semiactive control devices, like MR dampers, have been developed and applied to various structures in recent years [6-12]. The voltage-dependent nonlinear hysteretic behaviour allows MR dampers to be very flexible in resisting different levels of external force. A number of control studies have thoroughly investigated and modelled the command-force relationships for MR dampers [6]. Several analytical and experimental studies focusing upon the seismic protection of structures using MR dampers have also been published [13,14]. An inclusive goal of this study is to further validate the effectiveness of MR dampers in the application of structural control. A prototype wireless structural sensing and control system has been previously proposed [15] for structural response mitigation. The software written to operate the wireless sensors under the real-time requirements of the control problem is presented in detail herein. The promising performance of wireless communication and embedded computing technology within a real-time feedback structural control system is offered.

This paper presents the experimental verification of using both fully centralized control and fully decentralized control strategies within a structural control system assembled from semiactive control devices (MR dampers) and a wireless sensor network consisting of wireless sensors capable of actuation. An almost full-scale three-storey steel building with MR dampers installed upon each floor of the structure is tested by applying base motion using a six degree-of-freedom (DOF) shaking table. Structural responses are measured during seismic excitation by the wireless sensors and wirelessly communicated to wireless sensors interfaced to the system's MR damper. Embedded within each wireless sensor's computational core is linear quadratic Gaussian (LQG) control solution. Specifically, the following two major research directions are emphasized in this study:

1. The theoretical basis for fully centralized and fully decentralized control algorithms is offered for implementation within a wireless structural control system.

2. Experimental verification of wireless communications for real-time structural control is made and comparison of the control performance of the wireless control system is compared to that of a traditional tethered control system. 


\section{FORMULATION OF THE CONTROL PROBLEM}

The equation of motion for a building control system can be expressed as the state-space formulation. If a large-scale simulation of the structure is conducted using the finite element formulation, there would be many DOFs of the structure. However, to simplify the analysis of the system, a reduced-order dynamic model of the system is pursued. In this study, the reduced-order model is derived based upon a lumped mass system with lateral DOFs. The discrete-time representation of the reduced-order state-space equations can be represented as

$$
\begin{aligned}
z_{d}[k+1] & =A_{d} z_{d}[k]+B_{d} u[k]+E_{d} \ddot{x}_{g}[k] \\
y_{d, s}[k] & =C_{d} z_{d}[k]+D_{d} \ddot{x}_{g}[k]+F_{d} u[k]
\end{aligned}
$$

where $z_{d}[k]$ is the reduced-order state vector in discrete time, $A_{d}$ is the system matrix, $B_{d}$ is the matrix transformed from the continuous-time $b$ matrix and $E_{d}$ is related to the inertial distribution vector. The measurement output, $y_{d, s}$, consists of $C_{d}, D_{d}$, and $F_{d}$ matrices. In general, measurements such as displacement, velocity, and acceleration responses, can be chosen arbitrarily as the system output. In this particular study, the reduced-order model is a three DOF lump mass shear structure model; two different control algorithms (centralized and decentralized) will be derived using the model and absolute acceleration measurements as feedback.

\subsection{Fully centralized control of structural system}

For fully centralized control, the entire structural system and all system outputs are available for the calculation of optimal control forces. Every control force is calculated as a function of the full state vector, $z_{d}$. Since the full-state cannot be practically acquired in current structural control systems, the Kalman estimator is used to transform the measured output vector of the system into an estimated state vector. The estimated state response is then used by the control system to calculate the control forces based upon a linear gain matrix, $G$. Such an approach to feedback control is termed LQG regulation and based upon $\mathrm{H}_{2}$ control theory [16]. The linear gain matrix is found by minimizing a global objective function defined as

$$
J=\sum_{k=\text { initial time }}^{k \rightarrow \infty} z_{d}^{\mathrm{T}}[k] Q z_{d}[k]+u^{\mathrm{T}}[k] R u[k]
$$

where $Q$ and $R$ are positive definite matrices that achieve a relative weighting between the system response and the control effort needed to attain the response, respectively. Minimization of the $J$ function when constrained by the equation of motion of the system, the following Ricatti equation is derived:

$$
A_{d}^{\mathrm{T}} P A_{d}-A_{d}^{\mathrm{T}} P B_{d}\left(2 R+B_{d}^{\mathrm{T}} P B_{d}\right)^{-1} B_{d}^{\mathrm{T}} P A_{d}+2 Q=P
$$

The Ricatti equation is used to calculate the Ricatti matrix, $P$, which is an integral component of the determination of the control force at the $k$ th time step

$$
u[k]=-\left(2 R+B_{d}^{\mathrm{T}} P B_{d}\right)^{-1} B_{d}^{\mathrm{T}} P A_{d} z_{d}[k]=G z_{d}[k]
$$


where $G$ is the control gain (it should be noted that the gain matrix, $G$, will have dimension $3 \times 6$ in this case study). As is evident from Equation (4), the control force is calculated from the full-state vector. Considering the limited number of sensors in the structure that constitute the system output, $y_{d}$, a Kalman estimator is adopted to estimate the full-state response, $\hat{z}_{d}$, based upon the system output

$$
\widehat{z}_{d}[k+1]=A_{d} \widehat{z}_{d}[k]+B_{d} u[k]+L\left(y_{d, s}[k]-C_{d} \widehat{z}_{d}[k]-F_{d} u[k]\right)
$$

Here, $L$ is the solution of the Ricatti equation corresponding to the Kalman estimator formulation [17]. The control force can then be replaced by the following form:

$$
\begin{aligned}
u[k+1] & =G z_{d}[k+1]=G\left(A_{d}+B_{d} G-L C_{c}-L F_{d} G\right) z_{d}[k]+G L y_{d}[k] \\
& =G \hat{A}_{\mathrm{cs}} \hat{z}[k]+G L_{\mathrm{ms}} y[k]
\end{aligned}
$$

where $\hat{A}_{\mathrm{cs}}$ is the modified system matrix in relation to control and $L_{\mathrm{ms}}$ is the Kalman estimator in relation to the system measurements. As seen in Equation (6), the control force is generated using the full-state response vector. Since each actuator (which corresponds to each row of the gain matrix) requires the full-state response to determine its control action, this control approach assumes a fully centralized control architecture.

\subsection{Fully decentralized control of structural system}

Fully decentralized control emphasizes control of the local sub-system only using the sub-system's actuators and sensor measurements. It is to mitigate the response of the structure using limited information (partial state information) and independent controllers corresponding to sub-systems of the global structure. The control force generated by a sub-system controller would inherently be independent from those of the other sub-systems. A main advantage of decentralized control architectures is that sub-system controllers are independent; the malfunction of an individual controller will not cause the failure of whole control system. In exchange for the reliability offered by decentralized control methods is that their control performance is below that of their centralized counterparts. Within the structural control community, a number of researchers have explored decentralized approaches to the complex control problem [11,12].

To formulate a decentralized control solution, the discrete-time state-space equation is rewritten as

$$
\begin{aligned}
& z_{d}[k+1]=A_{d} z_{d}[k]+\sum\left(B_{d}\right)_{i} u_{i}[k]+E_{d} \ddot{x}_{g}[k] \\
& \left(y_{d, s}\right)_{j}[k]=\left(C_{d}\right)_{j} z_{d}[k]+\left(D_{d}\right)_{j} \ddot{x}_{g}[k]+\sum\left(F_{d}\right)_{j, i} u_{i}[k]
\end{aligned}
$$

where ' $j$ ' indicates $j$ th sub-system and ' $I$ ' indicates $i$ th locations of actuator, and $y_{j}$ indicates the measured output of the $j$ th sub-system of the measurement system. Let it be assumed that for each sub-system, there is one control actuator which applies a control force. The control force of the $i$ th actuator is denoted as $u_{i}$ and its control action seeks to minimize the following objective function:

$$
J_{i}=\sum_{k=\text { initial time }}^{k \rightarrow \infty} z_{d}^{\mathrm{T}}[k] Q z_{d}[k]+u_{i}^{\mathrm{T}}[k] \widehat{R} u_{i}[k]
$$


Here, $\widehat{R}$ is a scalar weighting term and may be different for each actuator depending upon the objectives of the specific actuator. The number of objective functions is the same as the number of sub-systems defined in the global structure.

Consider a three-storey structure where each floor is considered a sub-system within the control system. If an actuator and sensor (measuring acceleration) are collocated upon each floor of the structure, each floor can be considered its own sub-system. Provided three sub-systems, the global state-space equation and the measurement output equations corresponding to each sub-system (i.e. floor) can be written as follows:

$$
\begin{aligned}
z_{d}[k+1] & =A_{d} z_{d}[k]+\sum_{i=1}^{3}\left(B_{d}\right)_{i} u_{i}[k]+E_{d} \ddot{x}_{g}[k] \\
y_{1}[k] & =\left(C_{d, 1}\right)_{1 \times 6} z_{d}[k]+\left(D_{d, 11}\right)_{1 \times 1} u_{1}[k]+\sum_{j=2}^{3}\left(D_{d, 1 j}\right)_{1 \times 1} u_{j}[k]+\left(F_{d, 1}\right)_{1 \times 1} \ddot{x}_{g}[k] \\
y_{2}[k] & =\left(C_{d, 2}\right)_{1 \times 6} z_{d}[k]+\left(D_{d, 22}\right)_{1 \times 1} u_{2}[k]+\sum_{j=1,3}\left(D_{d, 2 j}\right)_{1 \times 1} u_{j}[k]+\left(F_{d, 2}\right)_{1 \times 1} \ddot{x}_{g}[k] \\
y_{3}[k] & =\left(C_{d, 3}\right)_{1 \times 6} z_{d}[k]+\left(D_{d, 33}\right)_{1 \times 1} u_{3}[k]+\sum_{j=1}^{2}\left(D_{d, 3 j}\right)_{1 \times 1} u_{j}[k]+\left(F_{d, 3}\right)_{1 \times 1} \ddot{x}_{g}[k]
\end{aligned}
$$

Here, the matrix $\left(C_{d, 1}\right)_{1 \times 6}$ corresponds to the first row (with dimensions $1 \times 6$ ) of the discrete-time matrix $C_{d}$ of Equation (4); the other matrix notations follow the same convention. The objective function, $J_{i}$, for the $i$ th floor can be written for all three floors as

$$
\begin{aligned}
& J_{1}=\sum_{k=0}^{\infty} z_{d}^{\mathrm{T}}[k] Q_{6 \times 6} z_{d}[k]+u_{1}^{\mathrm{T}}[k] \widehat{R}_{1 \times 1} u_{1}[k] \\
& J_{2}=\sum_{k=0}^{\infty} z_{d}^{\mathrm{T}}[k] Q_{6 \times 6} z_{d}[k]+u_{2}^{\mathrm{T}}[k] \widehat{R}_{1 \times 1} u_{2}[k] \\
& J_{3}=\sum_{k=0}^{\infty} z_{d}^{\mathrm{T}}[k] Q_{6 \times 6} z_{d}[k]+u_{3}^{\mathrm{T}}[k] \widehat{R}_{1 \times 1} u_{3}[k]
\end{aligned}
$$

Each objective function will derive an optimal gain matrix that corresponds to the objectives of the sub-system actuator. The Ricatti equation derived from the $i$ th sub-system objective function can be presented as

$$
A_{d}^{\mathrm{T}} P A_{d}-A_{d}^{\mathrm{T}} P\left(B_{d, i}\right)_{6 \times 1}\left(2 \widehat{R}_{1 \times 1}+B_{d}^{\mathrm{T}} P\left(B_{d, i}\right)_{6 \times 1}\right)^{-1}\left(B_{d, i}\right)_{6 \times 1}^{\mathrm{T}} P A_{d}+2 Q=P
$$

Based upon the solution of the Ricatti equation, the control gain of the sub-system can be described as

$$
u_{i}[k]=-\left(2 \widehat{R}+B_{d, i}^{\mathrm{T}} P B_{d, i}\right)^{-1} B_{d, i}^{\mathrm{T}} P A\left(z_{d}\right)_{i}[k]=G_{1 \times 6}\left(z_{d}\right)_{i}[k]
$$

It should be noted that the gain matrix relating the full-state response to the $i$ th control force, $u_{i}$, has the dimensions of $1 \times 6$. To maintain the fully decentralized architecture, the communication of response data between the sub-systems does not occur. Therefore, a Kalman estimator is used to estimate the full-state response, $\hat{z}_{d}$, based upon the measured system output

$$
\left(\widehat{z}_{d}\right)_{i}[k+1]=A_{d} \widehat{z}_{d}[k]+\left(B_{d}\right)_{i} u_{i}[k]+L_{j}\left(\left(y_{d, s}\right)_{j}[k]-\left(C_{d}\right)_{j}\left(\widehat{z}_{d}\right)_{i}[k]-\left(F_{d}\right)_{j, i} u_{i}[k]\right)
$$


If control force of Equation (12) is substituted into Equation (13), the estimator can be rewritten as

$$
\left(\widehat{z}_{d}\right)_{i}[k+1]=\left(A_{d}+\left(B_{d}\right)_{i} G_{i}-L_{j}\left(C_{d}\right)_{j}-L_{j}\left(F_{d}\right)_{j, i} G_{i}\right)\left(\widehat{z}_{d}\right)_{i}[k]+L_{j}\left(y_{d, s}\right)_{j}[k]
$$

here subscript $i$ indicates the full state estimated by the $i$ th sub-system Kalman estimator. The estimated full state is then used to determine the optimal control force to be applied by the sub-system actuator

$$
u_{i}[k+1]=G_{i}\left(\hat{z}_{d}\right)_{i}[k+1]
$$

\section{THE EXPERIMENTAL SET-UP}

\subsection{Test structure}

A three-storey half-scale steel structure is designed and constructed at the National Center for Research on Earthquake Engineering (NCREE) in Taipei, Taiwan. As shown in Figure 1, the three-storey structure consists of a single bay with a $3 \mathrm{~m} \times 2 \mathrm{~m}$ floor area and $3 \mathrm{~m}$ tall stories. The structure is constructed using $\mathrm{H} 150 \times 150 \times 7 \times 10$ steel I-beam elements with each beamcolumn joint designed as a bolted connection. Concrete blocks are added and fastened to the floor diaphragms until the total mass of each floor is precisely $6000 \mathrm{~kg}$. The entire structure is constructed upon a large-scale NCREE shaking table capable of applying base motion in six independent DOFs. The structural behaviour is modelled using a lumped mass shear structure reduced-order structural model defined by three DOFs (i.e. the lateral displacement of each floor). Based on the response of the bare frame, the damping and stiffness matrices of a reduced-order model were identified using system identification techniques. The identified natural frequencies corresponding to the first three modes of the structure are $1.08,3.25$, and $5.06 \mathrm{~Hz}$, respectively.

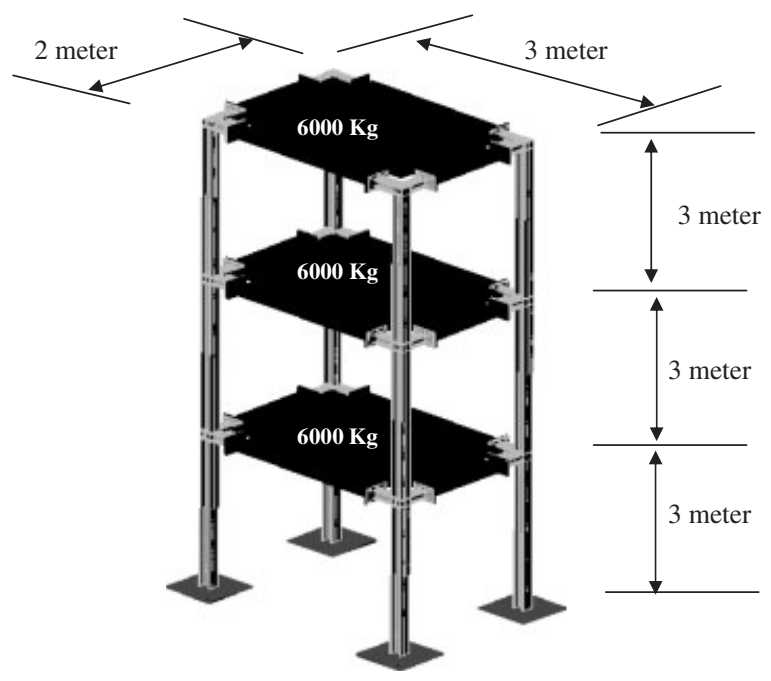

Figure 1. Benchmark structure for structural control research. 
Furthermore, the damping ratios of the first, second, and third modes are 1.6, 1.7, and 2.7\%, respectively. The identified natural frequencies are consistent with the mathematical model.

\subsection{The MR damper}

The magnetic field that controls the viscosity of the MR fluid is generated by the application of an electrical current to the coil surrounding the damper chamber. Therefore, higher damping coefficients can be attained by the MR damper simply by increasing the coil current. To render the MR damper compatible with a feedback control system, a VCCS (voltage current converter) unit will be needed to translate voltage command signals to the electrical current applied to the MR damper coil. In this study, the effects of temperature of the MR damper are not considered and the voltage-current conversion is assumed linearly proportional. Three $20 \mathrm{kN}$ MR dampers designed for the purposes of controlling the dynamic response of the test structure are constructed. MR dampers are inherently nonlinear devices that must be properly modelled prior to their use within a control system. Prior study of the MR dampers constructed reveals the suitability of using a modified Bouc-Wen model to express their force-velocity functions [18]. The total restoring force of the Bouc-Wen damper model is expressed as

$$
\tilde{F}(k)=z(k)+C \dot{x}(k)
$$

and

$$
\begin{aligned}
z(k) & =z(k-1)+\sum_{i=1}^{5} \theta_{i}(k-1) \phi_{i}(k-1) \mathrm{d} t \\
\phi(k) & =\Delta t *\left[\dot{x}(k),|\dot{x}(k)||z(k)|^{0} z(k), \dot{x}(k)|z(k)|^{1},|\dot{x}(k)||z(k)|^{1} z(k), \dot{x}(k)|z(k)|^{2}\right]^{\mathrm{T}}
\end{aligned}
$$

where $C$ is a voltage-dependent parameter and $z(t)$ is the damper's restoring force. The vector, $\phi$, consists of combinations of the damper response variables and is updated at each time step. Based on experimental data of the $20 \mathrm{kN}$ MR-damper from several random displacement and random voltage tests, the voltage-dependent parameter vector $\theta(V)=\left[\theta_{1}, \theta_{2}, \theta_{3}, \theta_{4}, \theta_{5}\right]$ has been identified by a regression analysis of the random displacement and random voltage test data; the voltagedependent model parameters are shown in Table I for each of the three MR dampers used in this study. Each table tabulates the model parameters for seven levels of command voltages ranging from 0 to $1.2 \mathrm{~V}$. The accuracy and robustness of the identified Bouc-Wen model parameters were verified. Figure 2 shows the comparison between the measured and the simulation data corresponding to the force versus displacement relationship and the force versus velocity relationship of MR-damper based on the random displacement and random voltage validation test. The proposed model can predict the damper behaviour quite well, even for the case of a random voltage input.

\subsection{WiSSCon system design}

WiSSCon (wireless structural sensing and control system) is an academic prototype system designed for real-time wireless structural sensing and feedback control [3, 15]. Within the WiSSCon system, wireless communication is used to broadcast data from wireless sensors collecting structural response measurements to wireless sensors serving as controllers (i.e. wireless sensors interfaced to the MR-damper VCCS unit). The wireless sensor prototype selected as the building block of the WiSSCon system is designed to: collect measurement data from sensors interfaced; command 
Table I. Identified frequency-dependent model parameters of MR-damper.

\begin{tabular}{|c|c|c|c|c|c|c|}
\hline Voltage (V) & $C$ & $\theta_{1}$ & $\theta_{2}$ & $\theta_{3}$ & $\theta_{4}$ & $\theta_{5}$ \\
\hline \multicolumn{7}{|c|}{ Parameters of Bouc-Wen model for first floor } \\
\hline 0 & 0.005 & 1.0762 & -389.272 & -160.45 & -0.7757 & -0.316 \\
\hline 0.2 & 0.00666 & 2.0945 & -413.479 & -194.5 & -2.4071 & -1.6572 \\
\hline 0.4 & 0.00832 & 4.3122 & -450.615 & -228.95 & -4.0899 & -2.9708 \\
\hline 0.6 & 0.00998 & 7.0912 & -500.68 & -263.81 & -5.8242 & -4.2567 \\
\hline 0.8 & 0.01164 & 9.7936 & -563.672 & -299.07 & -7.61 & -5.5151 \\
\hline 1 & 0.0133 & 11.781 & -639.593 & -334.73 & -9.4472 & -6.7458 \\
\hline 1.2 & 0.01496 & 12.416 & -728.443 & -370.8 & -11.3359 & -7.9489 \\
\hline \multicolumn{7}{|c|}{ Parameters of Bouc-Wen model for second floor } \\
\hline 0 & 0.025 & 1.19061 & -248.031 & -196.815 & -1.33927 & -1.21679 \\
\hline 0.2 & 0.04 & 2.12197 & -234.314 & -145.554 & -3.07141 & -2.30368 \\
\hline 0.4 & 0.05 & 4.73037 & -325.972 & -201.944 & -5.40836 & -4.2225 \\
\hline 0.6 & 0.06 & 6.83568 & -366.711 & -244.392 & -6.65451 & -5.7088 \\
\hline 0.8 & 0.06 & 9.55933 & -436.549 & -272.294 & -9.45087 & -7.56334 \\
\hline 1 & 0.08 & 6.2218 & -244.145 & -160.267 & -5.25377 & -4.50831 \\
\hline 1.2 & 0.1 & 5.66615 & -233.645 & -143.612 & -5.79513 & -4.44587 \\
\hline \multicolumn{7}{|c|}{ Parameters of Bouc-Wen model for third floor } \\
\hline 0 & 0.002 & 0.025653 & -26.2894 & -7.96593 & -0.09007 & -0.03318 \\
\hline 0.2 & 0.002 & 0.723013 & -133.913 & -51.8101 & -1.08821 & -0.54494 \\
\hline 0.4 & 0.002 & 1.754729 & -207.979 & -80.4538 & -2.19748 & -1.12879 \\
\hline 0.6 & 0.002 & 3.204114 & -283.521 & -109.642 & -3.70813 & -1.92584 \\
\hline 0.8 & 0.004 & 4.041636 & -318.893 & -128.528 & -4.459 & -2.48754 \\
\hline 1 & 0.008 & 6.413417 & -470.966 & -197.711 & -5.2089 & -3.79919 \\
\hline 1.2 & 0.009 & 9.935092 & -572.313 & -277.263 & -9.91404 & -6.72332 \\
\hline
\end{tabular}

actuators using analog voltage signals; store and process measurement data; and wirelessly communicate data to other wireless sensors. The hardware design of the wireless sensor is presented in Figure 3(a) with individual hardware components specified. With respect to the WiSSCon system, the actuation interface and the computational core of the wireless sensor design are most important. The actuation interface consists of a dual-channel 16-bit digital-to-analog converter (DAC) and support electronics offering analog output voltage signals that can span from -5 to $5 \mathrm{~V}$. The computational core of the wireless sensor is designed around the low-power 8-bit Atmel ATmega128 microcontroller and it is responsible for the calculation of optimal control forces and determination of the appropriate MR damper voltage signal based upon the parametric BoucWen damper model. The wireless sensor is capable of performing three operational tasks. First, the wireless sensor can collect response data from sensors (e.g. accelerometers) interfaced using its four-channel 16-bit analog-to-digital converter (ADC). Upon measurement of the structural response, the wireless sensor is responsible for broadcasting its data when a centralized control architecture is adopted. Second, the wireless sensors can determine the control force based upon the LQG control solution embedded in its computational core. Once a desired control force has been identified, the modified Bouc-Wen model of the MR damper is used to determine the damper voltage corresponding to the desired control force. Finally, the necessary voltage level is issued to the MR damper by the wireless sensor's actuation interface. Regardless of the task assigned to each wireless sensor in the WiSSCon system, all of the tasks must be completed within the allotted 

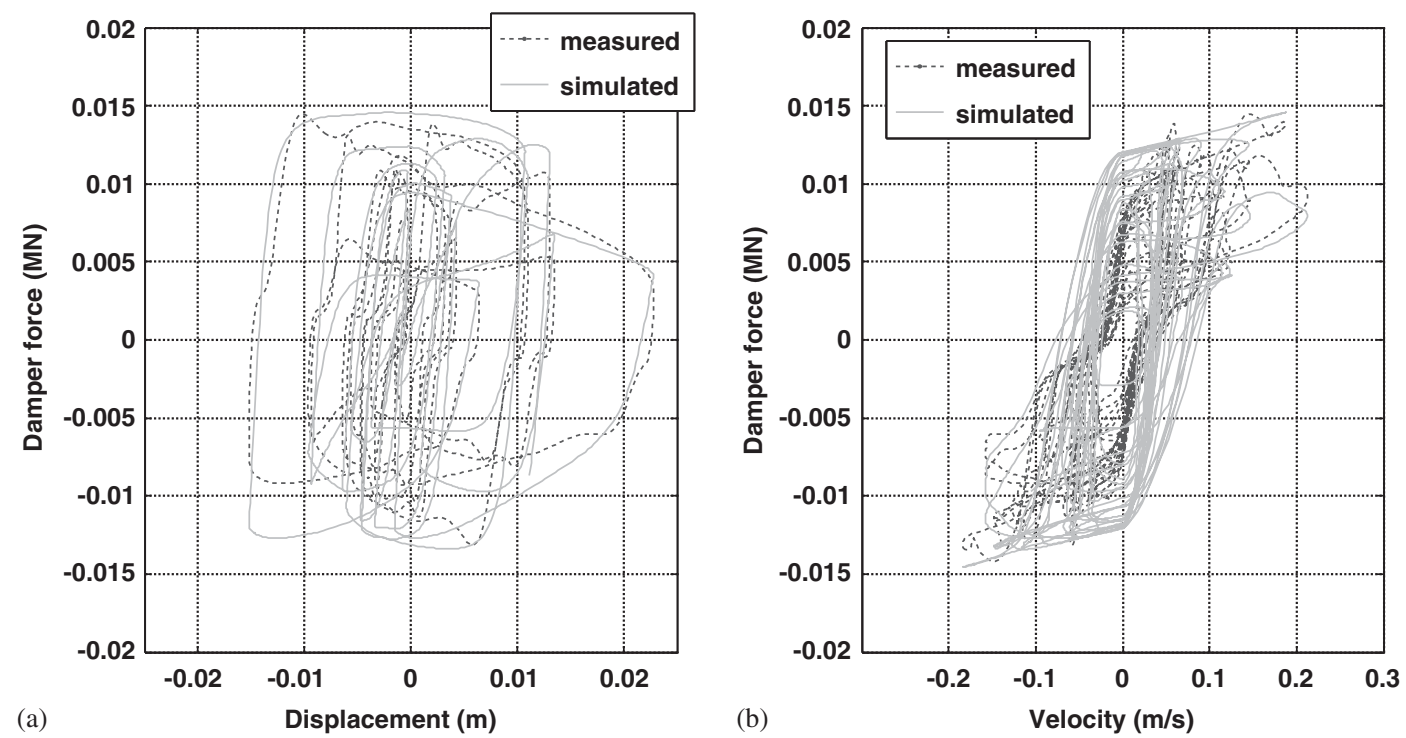

Figure 2. Comparison between the measured data and the simulation result on: (a) force versus displacement relationship and (b) force versus velocity relationship, from random stroke random voltage test of MR damper.

time step to ensure the system operates in real time. In addition to wireless sensors installed in the test structure, a data server (e.g. laptop computer) with a $2.4 \mathrm{GHz}$ MaxStream 24XStream wireless transceiver interfaced is employed to commence operation of the WiSSCon system and to serve as a data logger that logs the response data broadcast by the wireless sensors at each time step.

Two pieces of software are written to automate the operational tasks of the WiSSCon system. First, software that automates the wireless sensors is written and embedded in their computational cores; this software is referred to as the embedded code. An additional software package is written for the data server and is termed the server code. To illustrate the operation of the WiSSCon system and the inter-dependencies of the server and embedded codes, the flow of the system's software tasks is presented in Figure 4(a). The program flow can be broadly summarized in the following five steps:

Step 1: Initialized the WiSSCon system before operation. When the wireless sensors are turned on they are programmed to initialize their hardware and to wait for a command from the data server. Similarly, the server code is manually initiated on the data logger. The boot up procedure of the server code consists of reading the set-up file of the WiSSCon system where information on the system (e.g. number of sensors, number of actuators, sample rate) is stored.

Step 2: With the data server and wireless sensors initialized, the server confirms the availability of the wireless sensors by querying them to communicate their status. Once the server can establish that all of the wireless sensors are operational, it resets its counter to zero. Figure 4(b) provides an overview of the sequence of communication between the server and the wireless sensors.

Step 3: The control system starts operation by having the data server broadcast a beacon signal. Upon receipt of the beacon signal, each wireless sensor is aware of the new time step and begins 

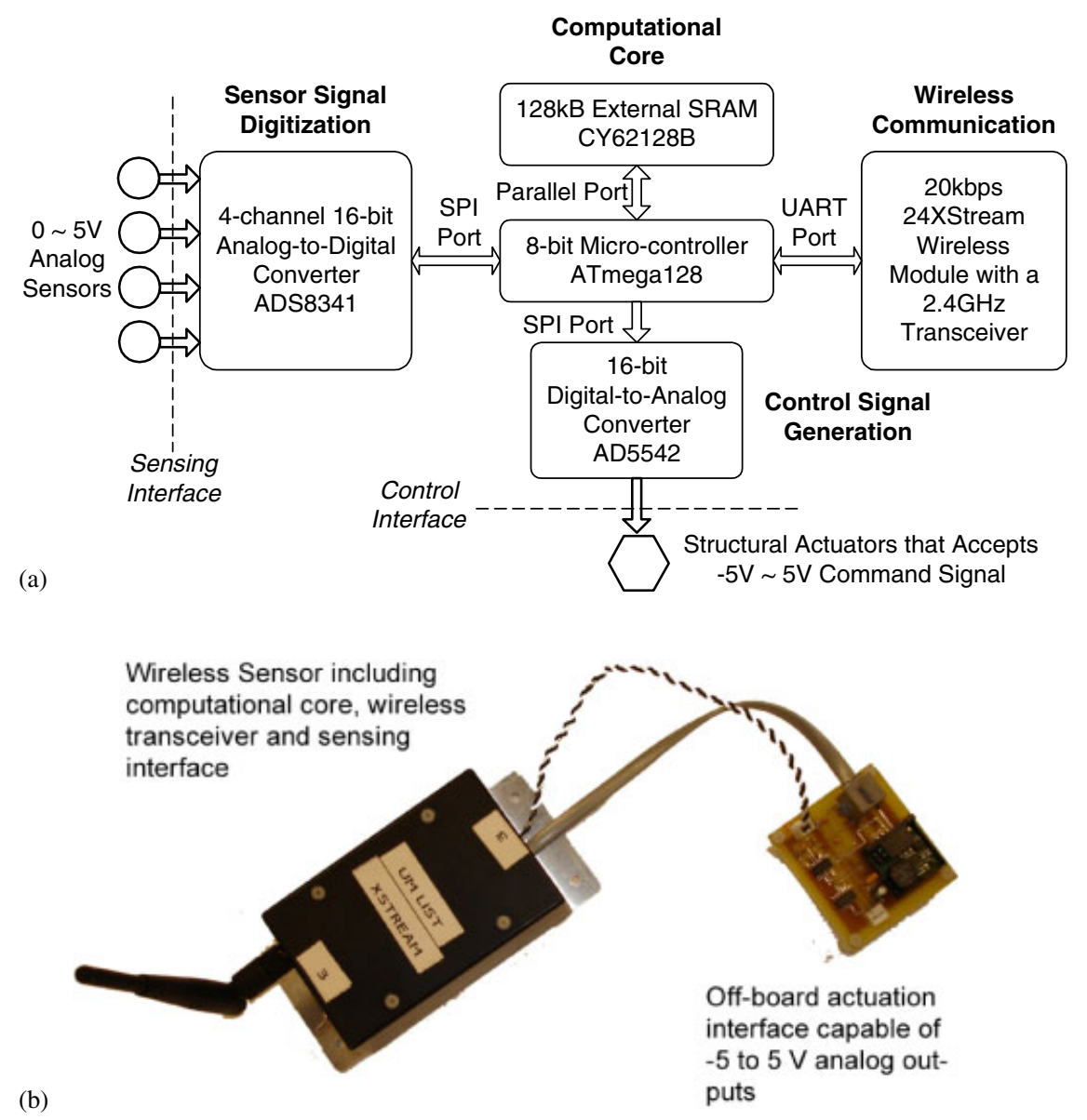

Figure 3. Architecture of wireless control unit: (a) hardware architectural design and (b) picture of wireless sensor prototype prior to installation in the test structure [15].

its autonomous operation (i.e. collect data, communication data, calculate control forces, and issue commands to the MR dampers). Each wireless sensor is provided a time window during which it can broadcast its response data. The units communicate in sequential order with the first floor's wireless sensor communicating first, the second floor wireless sensor communicating second, and the third floor wireless sensor communicating last. After the response data of the structure has been broadcast by all of the wireless sensors, the wireless sensors that receive the data include it in their LQG control algorithm for determination of the control action. In this system, time is maintained by the data server. As such, the data server issues the beacon signal at a fixed sample rate to designate the beginning of a time step. Step 3 is repeated continuously for a fixed amount of time the user specifies at the data server.

Step 4: After the time duration specified by the system end-user is complete, the data server queries each wireless sensor to send data the sensor locally logged during its operation. Data such 


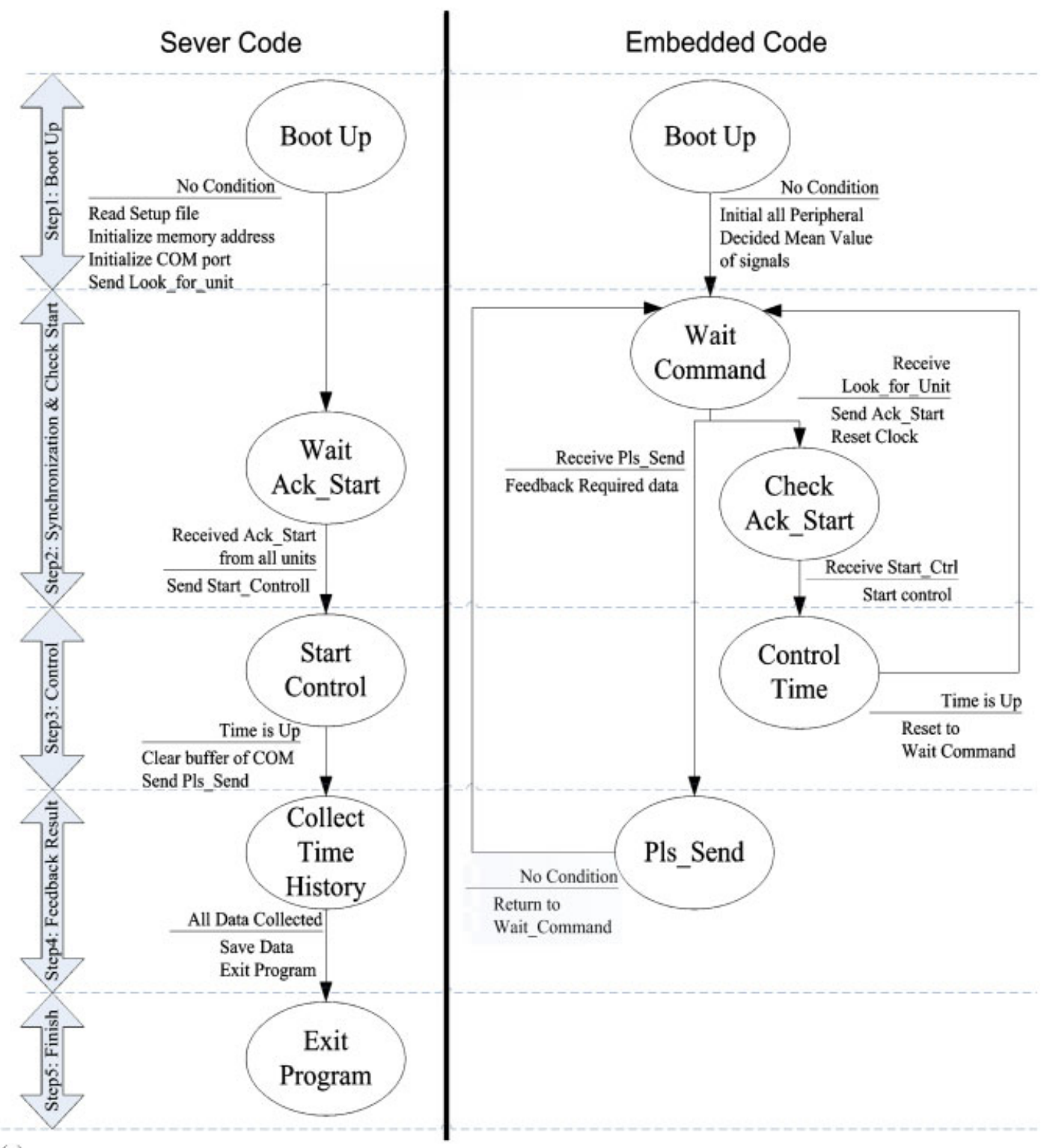

(a)

Figure 4. (a) Four steps for Server's time flow to boot up and reset clock/counter and for embedded code to start control test and (b) description on Step 2 (synchronization and check start), Step 3 (time required to collect data) and Step 4 (feedback results) in server code and embedded code.

as the response data measured by the wireless sensor, response data wirelessly received by the other nodes, desired control force and applied MR damper voltage signal are all returned to the data server by each wireless sensor. 


\section{Step2}

Synchronization \& Check Start

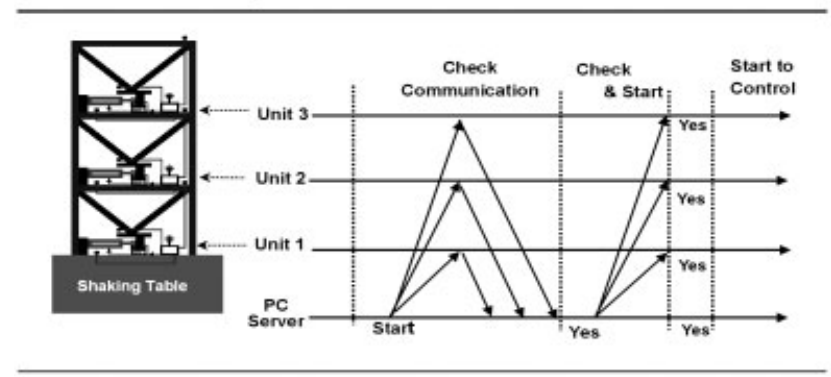

Step3

For Centralized Control

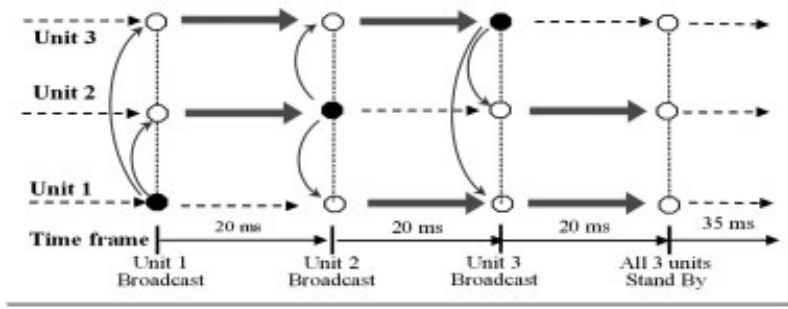

Step4

Feedback Results

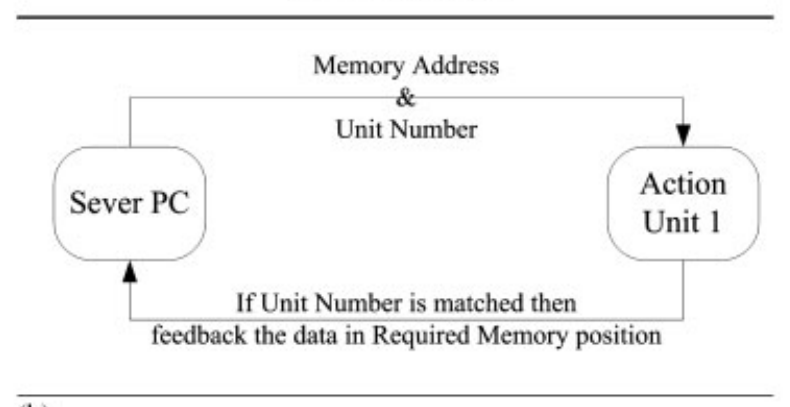

(b)

Figure 4. Continued.

Step 5: After the data server has received the data from the wireless sensor nodes of the WiSSCon system, the data server exits its program.

The communication latency between each wireless sensor needs to be carefully considered when discussing the real-time performance of the wireless control system. Each wireless communication takes approximately $20 \mathrm{~ms}$ to complete. As a result, when the system is configured to operate 
in a centralized fashion and data are to be broadcast from each floor of the structure, a total of $60 \mathrm{~ms}$ is needed at each time step. Calculating the control force may take a wireless sensor an additional $35 \mathrm{~ms}$. As a result, a total of $95 \mathrm{~ms}$ is required to reliably complete one time step in the centralized control architecture. Therefore, when the WiSSCon system is configured to operate in a centralized manner, the sample rate of $10 \mathrm{~Hz}$ is selected. A more detailed timing diagram for the centralized control architecture is provided in Figure 4(b). If the system is configured to operate as a fully decentralized control system, there is no need for communication between wireless sensors. With computations being the only limiting factor, the sample rate of the decentralized WiSSCon system is $50 \mathrm{~Hz}$.

\subsection{Control system set-up}

The WiSSCon control system consists of many elements including sensors (velocity meters to measure damper shaft velocities and accelerometers to measure floor accelerations), MR dampers, VCCS (voltage converts to current system), and the wireless sensors. Figure 5 describes the typical configuration of the system on one of the floors of the test structure. As can be seen, the MR damper is installed in a V-brace configuration providing damping forces upon the $i$ th and $(i+1)$ th floors. A wireless sensor node is installed upon each floor with three sensors interfaced. First, two velocity meters (Tokyo Sokushin VSE-15-AM servo velocity meter) measuring absolute velocity are connected to provide the sensor with a measure of the shaft velocity of the damper. This parameter is needed by the wireless sensor to update the damper restoring force using the modified Bouc-Wen model. Second, an accelerometer (Crossbow CXL01) is mounted to each floor to measure the lateral structural response to ground motion. This acceleration measurement is wirelessly communicated to the other wireless sensors when the control system implements a centralized control architecture. However, if a decentralized control architecture is employed, each floor is modelled as an independent sub-system with no communication occurring between wireless sensors.

At each time step, each wireless sensor measures its floor acceleration and the shaft velocity of the MR damper. If the WiSSCon system is operating in a centralized fashion, the wireless sensor sends its own acceleration and receives the acceleration of other floors. The acceleration response of the structure is then used by each wireless sensor to estimate the full-state response of the structure using the embedded Kalman estimator (Equation (8) for the centralized system and Equation (16) for the decentralized system). The desired control force to be applied by the MR damper is determined using the estimated state response (Equation (6) for the centralized system and Equation (14) for the decentralized system). Once the control force is calculated, each wireless sensor uses the modified Bouc-Wen model to determine the appropriate voltage to apply to the VCCS unit. Given the complexity of the Bouc-Wen model, the attainable control force the damper can generate is calculated at each time step for each of the seven voltage levels $(0-1.2 \mathrm{~V})$. The optimal control force determined by the LQG solution is then compared to this list of attainable control forces; the wireless sensor selects the voltage level offering the control force closest to that desired by the LQG controller. To ensure that the Bouc-Wen model is updated for the next time step, the wireless sensor updates the restoring force of the model using Equation (15). Figure 5(b) provides a flow chart of the flow of calculations made by each wireless sensor during the operation of the WiSSCon system. 

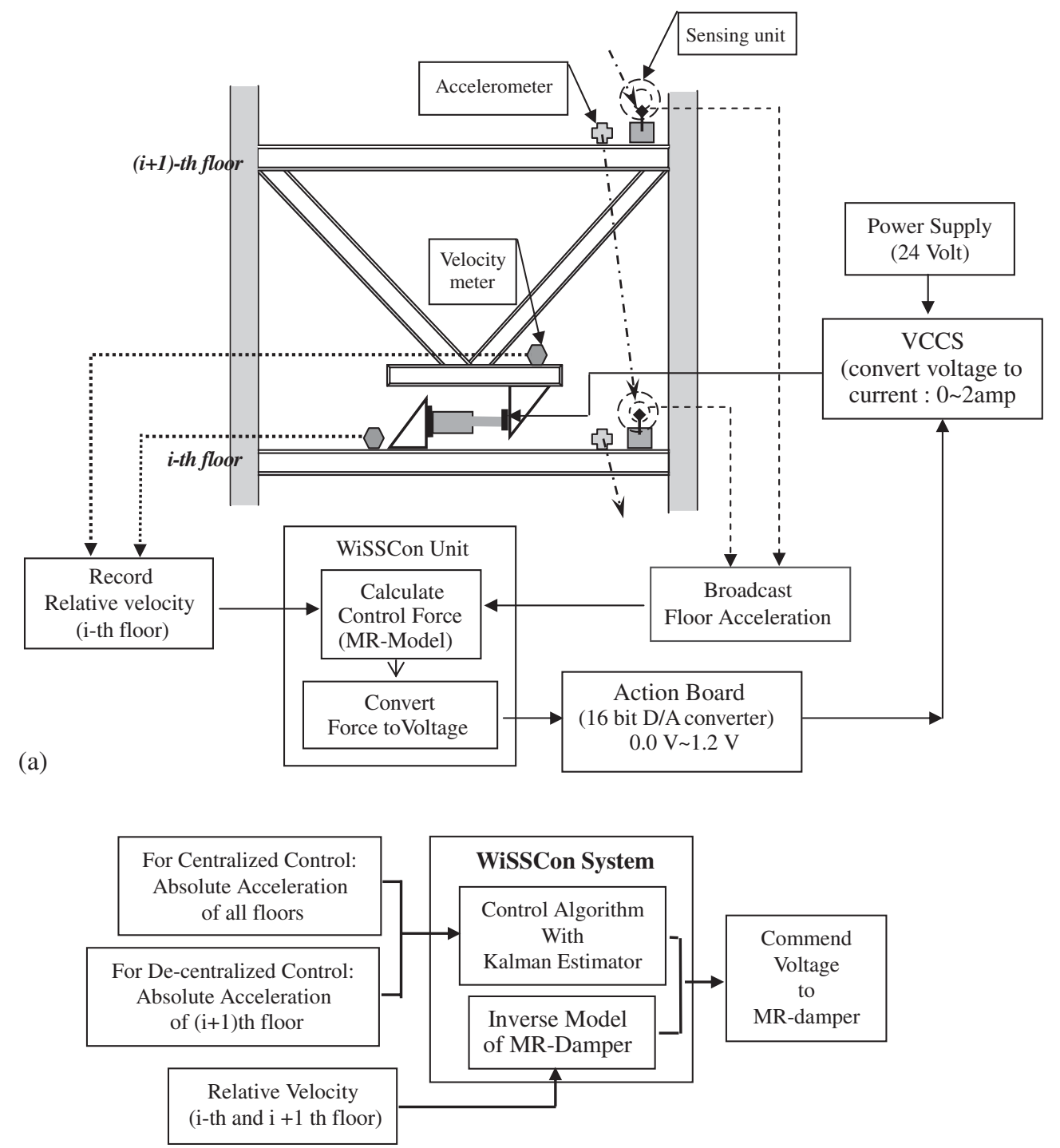

(b)

Figure 5. (a) Control set-up using wireless sensing and control unit and its connection with the control device (MR damper) and (b) flow of computing tasks conducted at each time step by the wireless sensor.

\section{DISCUSSIONS OF THE EXPERIMENTAL RESULTS}

From the shaking table test of the three-storey steel frame with the installation of an MR-damper on each floor, the control effectiveness of the wireless control system is examined. To provide a benchmark for comparison purposes, a wired control system using a wired data acquisition 


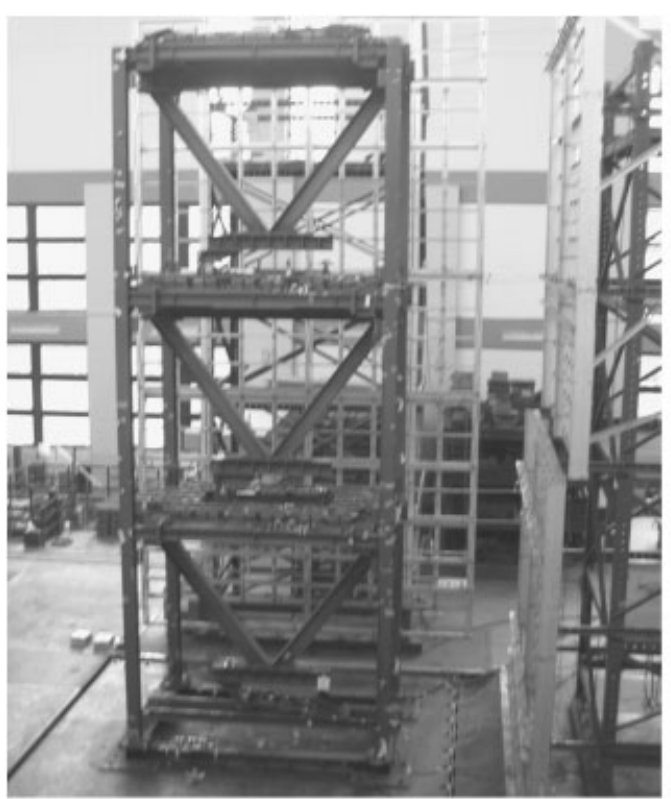

(a)

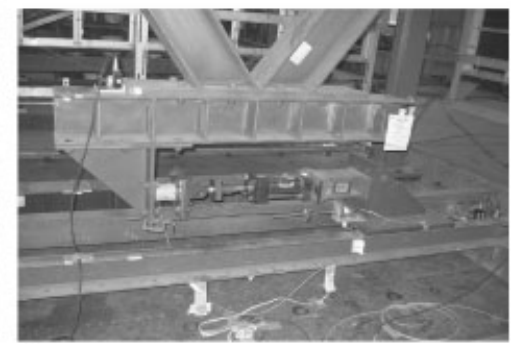

(b)

Figure 6. (a) Photo of the three-storey test structure on NCREE shaking table and (b) photo of the MR damper on the first floor.

permanently installed in the NCREE shaking table facility is implemented. An identical LQG control solution is implemented in the wired control system with the gain of the LQG controller and Kalman estimator adjusted to account for the wired system's sample rate of $200 \mathrm{~Hz}$. Figure 6 shows a photo of the test structure on shaking table. The stiffness of the MR damper V-brace is designed to be significantly larger than the stiffness of each floor; this ensures little deformation occurs in the steel bracing. In this control experiment, three different control systems will be implemented: (1) NCREE data acquisition system (Pacific Series 5500 Digital Conditioning System with a sample rate of $200 \mathrm{~Hz}$ ); (2) WiSSCon centralized control system (with a sample rate of $10 \mathrm{~Hz}$ ); and (3) WiSSCon decentralized control system (with a sample rate of $50 \mathrm{~Hz}$ ). A summary description of each of the three control systems is provided:

a. NCREE laboratory control system: A real-time control system is assembled by combining the NCREE digital acquisition system with a DSpace input/output interface board. A Simulink model is constructed to determine MR damper voltage commands (issued by the DSpace I/O board) using response measurements of the structure collected by the data acquisition system. The sampling rate for this control experiment (either centralized or decentralized control) is $200 \mathrm{~Hz}$ and the LQG control algorithm will be used. The result from this control system will be used for comparison with the wireless control system (centralized and decentralized).

b. Centralized wireless control with a sampling rate of $10 \mathrm{~Hz}$ : In the centralized architectural configuration of the WiSSCon system, the wireless sensors on each floor will measure their respective acceleration and broadcast that measurement to the other wireless sensors situated on different floors. If a high sample rate is chosen, then there is a chance data could be lost 
due to dropped packets or packet collisions in the wireless channel. To ensure data loss kept below $2 \%$, a sample rate of $10 \mathrm{~Hz}$ is used [15].

c. Decentralized wireless control with a sample rate of $50 \mathrm{~Hz}$ : In the decentralized control system, each wireless sensor only receives measurement data from the sensors on its own floor. Since there is no need to wait for the wireless transmission of data, the sample rate can be higher; a rate of $50 \mathrm{~Hz}$ is employed.

\subsection{Validation of the WiSSCon system}

In order to verify the measurement accuracy of the wireless control system (centralized and decentralized) and the validity of the embedded algorithms (specifically, the modified Bouc-Wen damper model), the wireless control system time histories will be compared to that redundantly recorded by the NCREE tethered data acquisition system. The El Centro (1940, NS) ground motion record scaled to a peak acceleration of $200 \mathrm{gal}$ is adopted during this study. Although the table has six DOFs, the ground motion is only applied in one lateral direction.

a. First, the command voltage issued by the wireless sensors and that measured by the laboratory data acquisition system shows one-to-one agreement. As presented in Figure 7, the command voltage calculated by the wireless sensor and applied to an MR damper during the El Centro earthquake record is identical to that measured by the tethered data acquisition system.
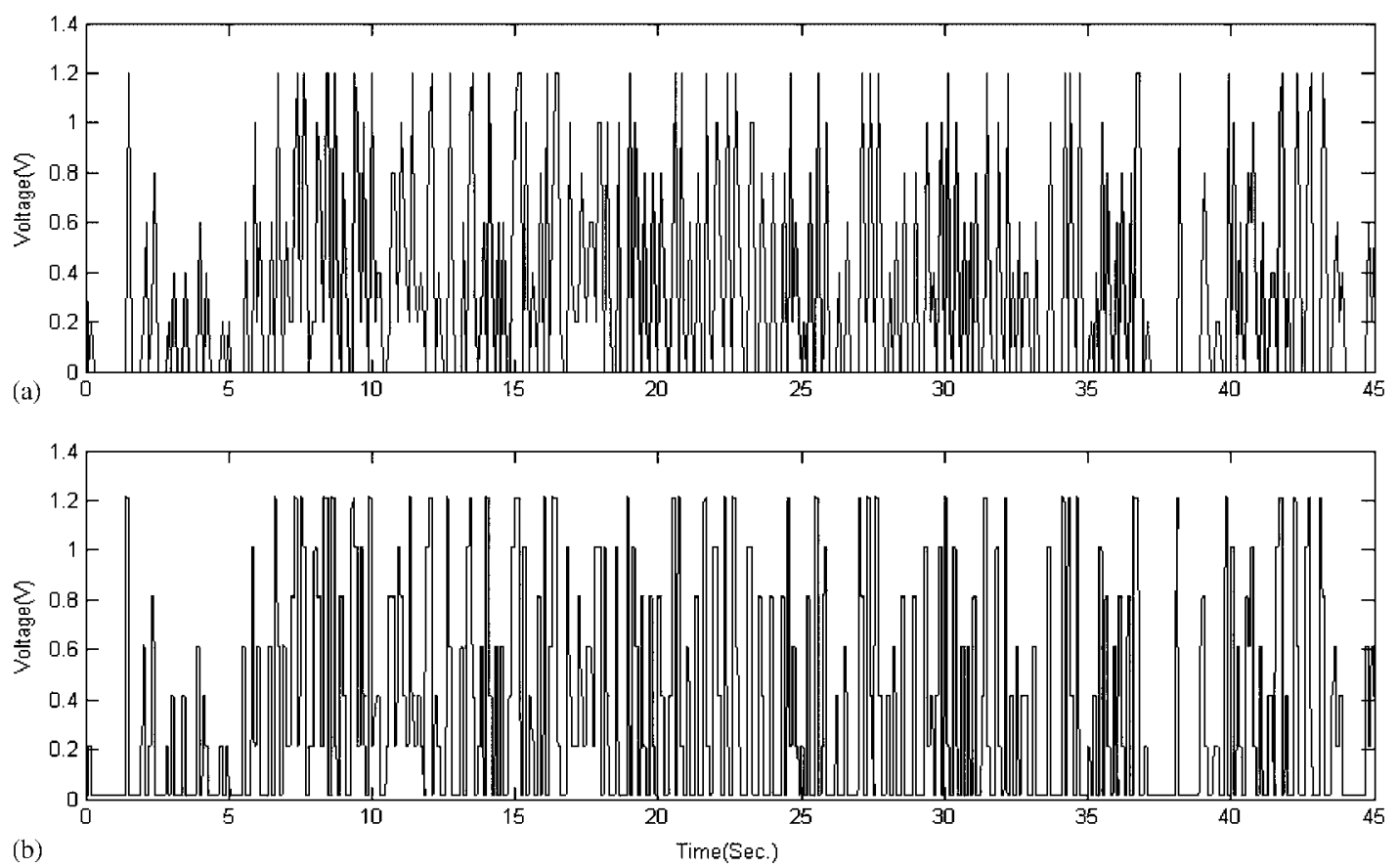

Figure 7. Comparison on the commend voltage: (a) decided by the microcontroller of the wireless system in digital format and (b) recorded by the wired system in NCREE from the output of action board in analog format. 

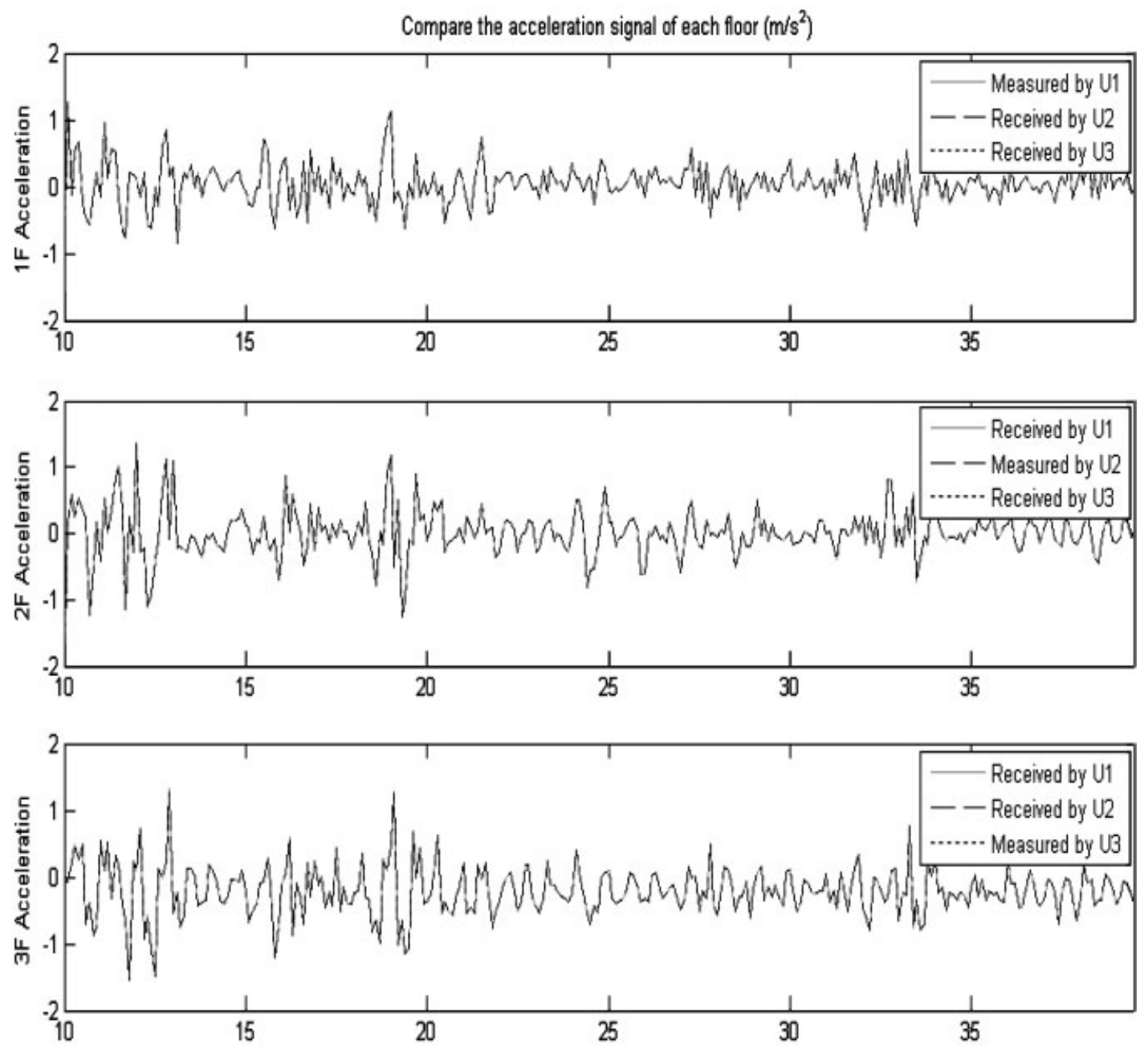

Figure 8. Comparison on acceleration data (plot from 10 to $40 \mathrm{~s}$ ) from measured as well as received from all sensing units (U1: sensing unit 1 on first floor, U2: sensing unit 2 on second floor, U3: sensing unit 3 on third floor).

b. Next, the acceleration response of the structure as measured by each wireless sensor is compared to the same acceleration response time-history wirelessly received by the other wireless sensors during an excitation. This comparison is intended to identify any issues associated with the communication of data in the wireless control system. As shown in Figure 8, the acceleration time histories are wirelessly received without error and data loss during excitation.

c. The accuracy of the LQG control solution embedded in the wireless sensor computational core is validated by comparing the voltage output from the wireless sensor to that theoretically calculated off-line using the response data recorded by the wireless sensor. This is done for 

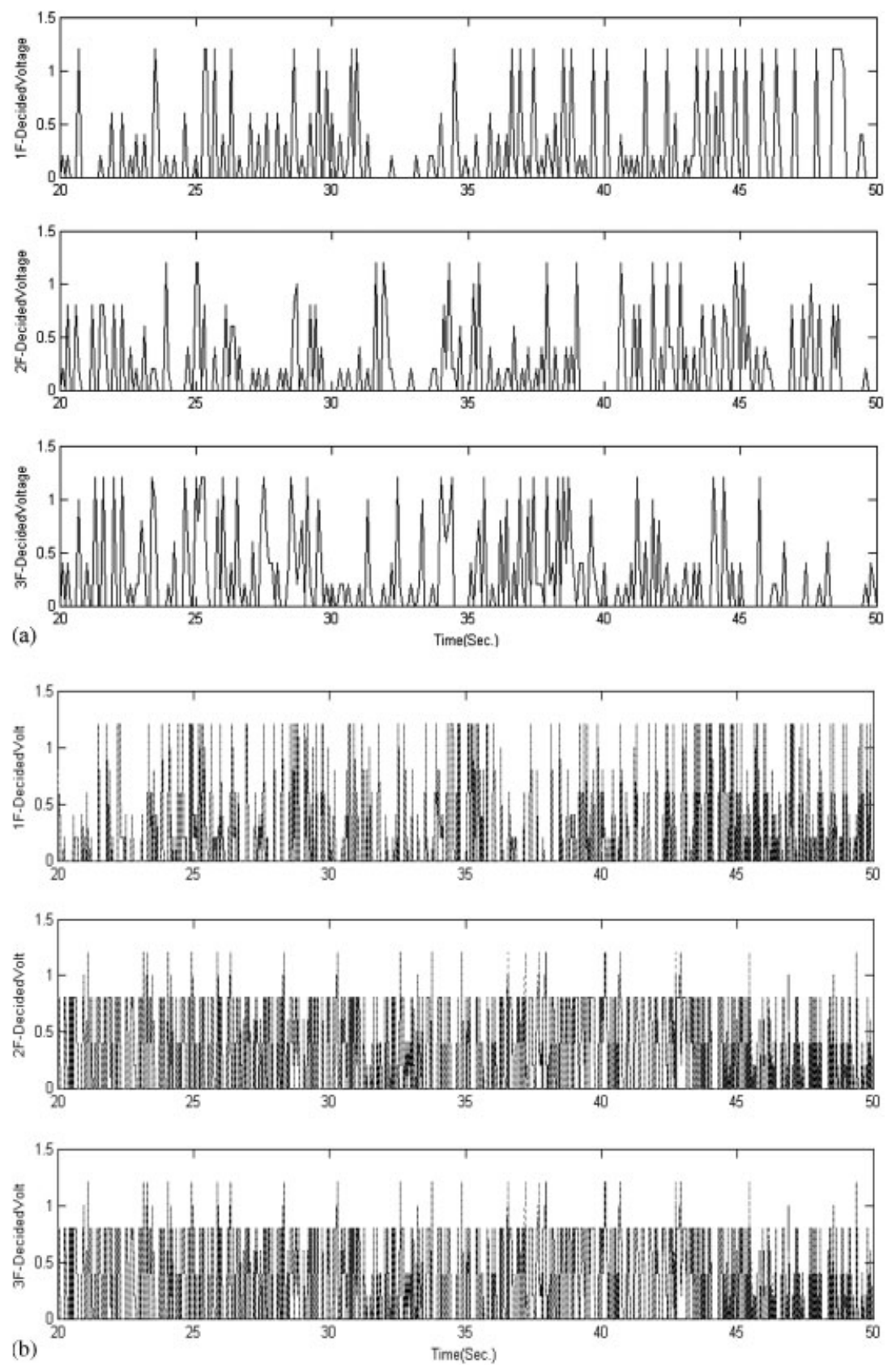

Figure 9. Comparison on the commend voltage (from 20 to $50 \mathrm{~s}$ ) between simulation and experiment under the EL-Centro earthquake excitation: (a) centralized control and (b) decentralized control. 

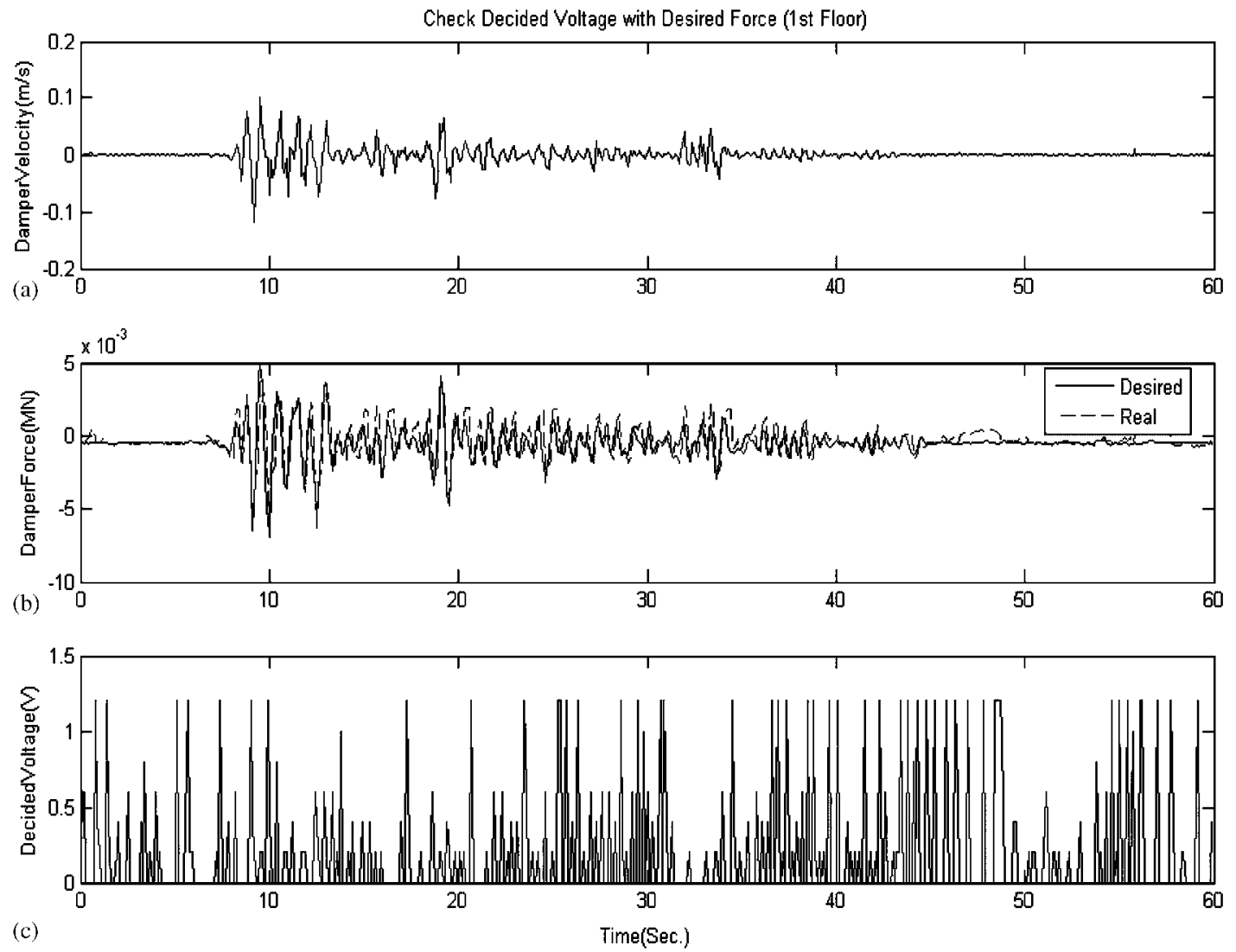

Figure 10. (a) Example shows the measured relative velocity (first floor) for MR-damper; (b) comparison between the calculated damper force from theoretical model (solid line) and the measured damper force from wireless system (dash line); and (c) decided voltage into the MR damper.

both the centralized and decentralized WiSSCon architectures. As shown in Figure 9, there is good agreement between the command voltage generated by the off-line numerical simulation and the experimentally obtained command voltage signal.

d. Similarly, the accuracy of the modified Bouc-Wen model in converting the LQG control force into a command voltage to be applied to the MR damper is verified. Figures 10(a) and (c) show the damper's shaft velocity and the voltage signal generated by the wireless sensor's Bouc-Wen model during the application of the El Centro ground motion record. As can be seen in Figure 10(b), the damper force measured by the laboratory data acquisition system from a load cell installed on the first floor MR damper (dash line) is in strong agreement with the LQG control force calculated by the wireless sensor (solid line).

From the above-mentioned validation tests, the WiSSCon system has proven that it can reliably command the correct voltage to attain a desired control force, that there is no loss of data during communication, and that the actuation interface is capable of generating the correct control voltage. 

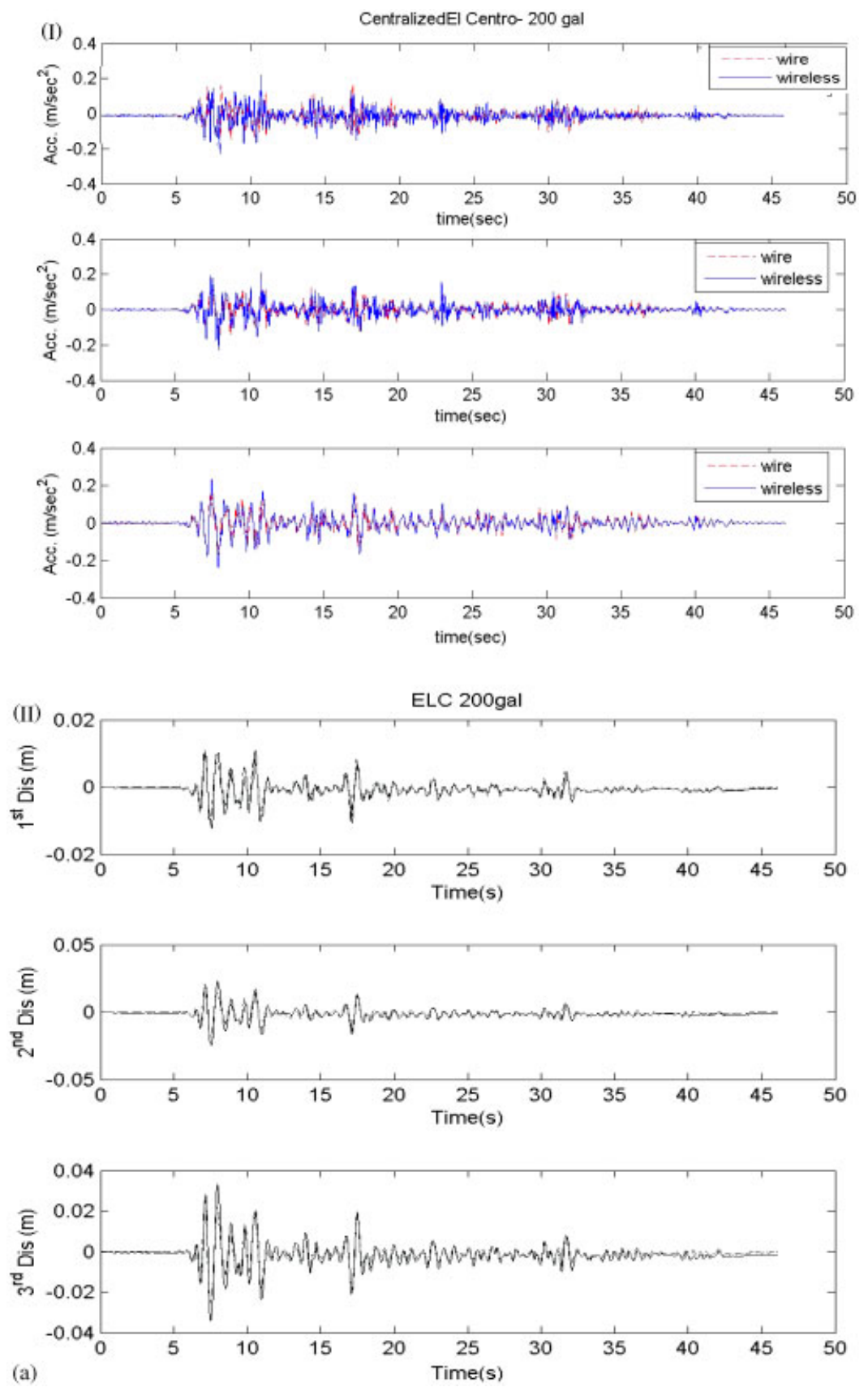

Figure 11(a). Comparison of the acceleration (I) and displacement (II) responses using wireless (10 Hz) and wired $(200 \mathrm{~Hz})$ centralized control. 

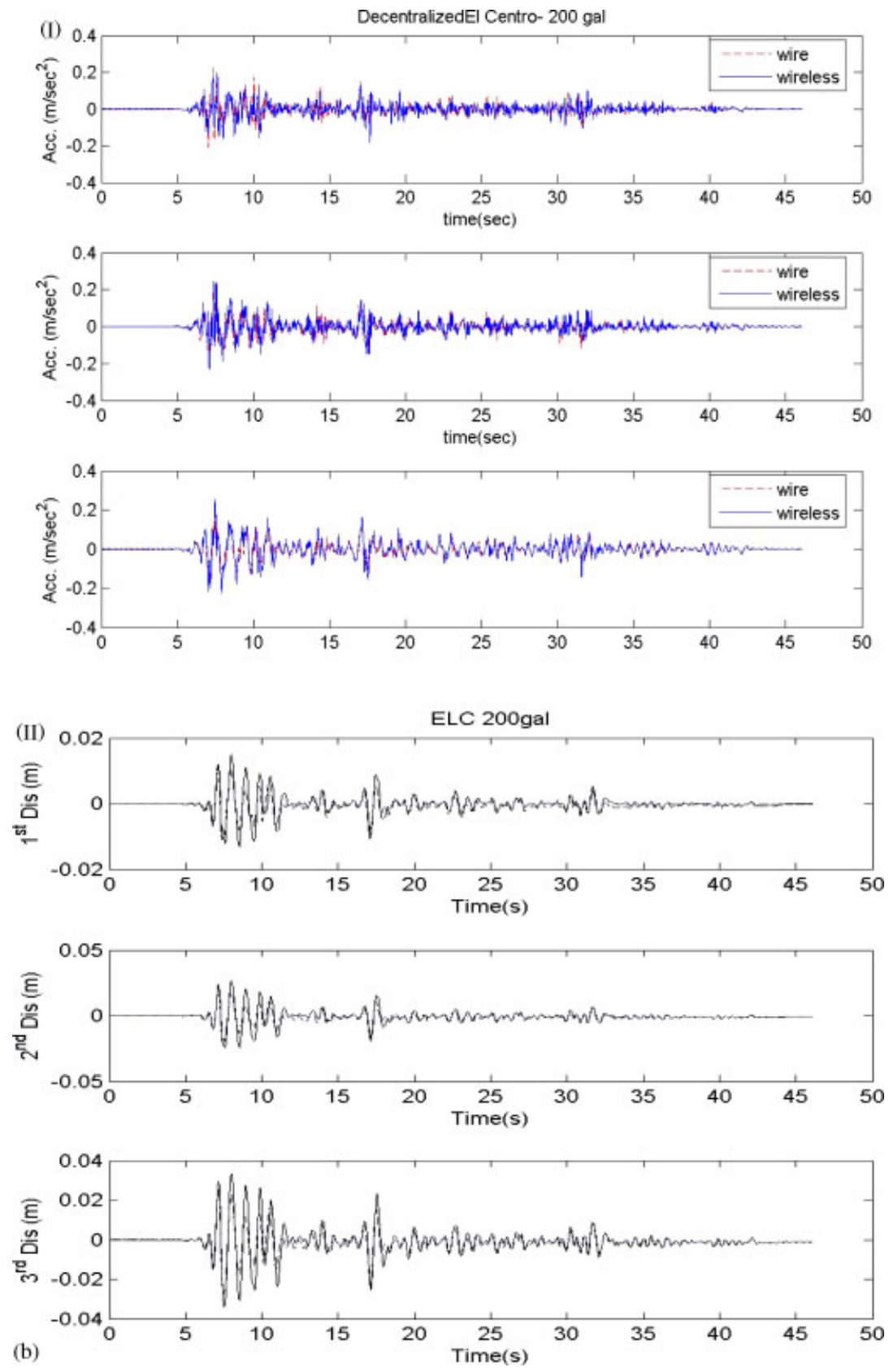

Figure 11(b). Comparison of the acceleration (I) and displacement (II) responses using wireless (50 Hz) and wired $(200 \mathrm{~Hz})$ decentralized control. 


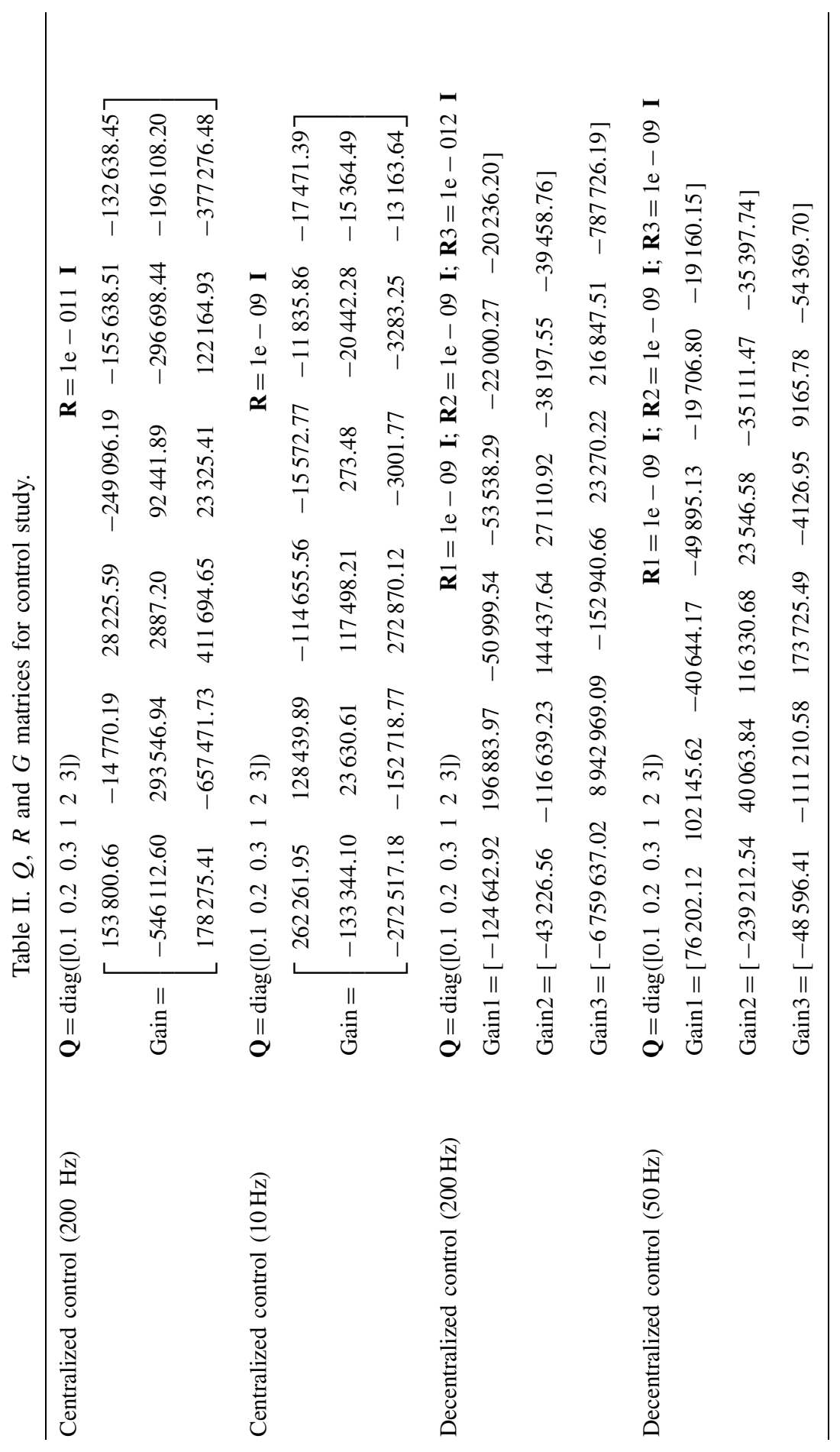

Copyright $@ 2007$ John Wiley \& Sons, Ltd.

Earthquake Engng Struct. Dyn. 2007; 36:1303-1328

DOI: $10.1002 /$ eqe 


Excitation Level: ElCentro earthquake (PGA=200gal)
\begin{tabular}{|c|c|c|c|c|c|c|c|}
\hline & P-0V & & P-1.2V & & Cen $10 \mathrm{~Hz}$ & & Cen $10 \mathrm{~Hz}$ - Wireless \\
\hline & Decen $50 \mathrm{~Hz}$ & & Decen $50 \mathrm{~Hz}$ - Wireless & $\square$ & Cen $200 \mathrm{~Hz}$ & $\square$ & Decen $200 \mathrm{~Hz}$ \\
\hline
\end{tabular}

Base Shear \& Over turning Moment (Peak)

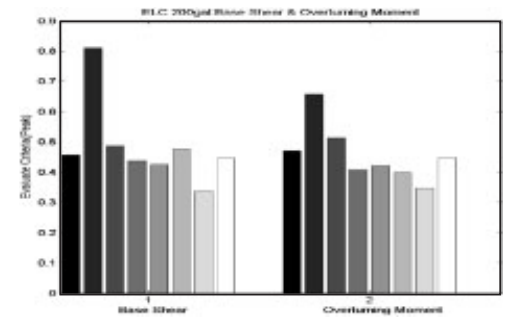

Absolute Acceleration (Peak)

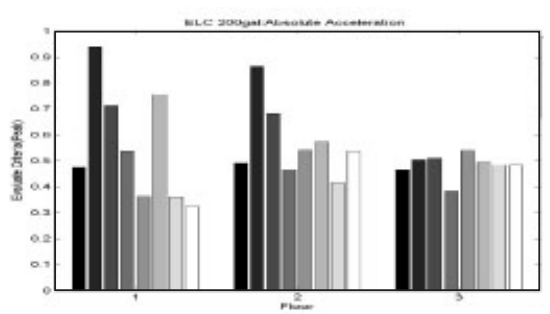

Relative Displace (Peak)

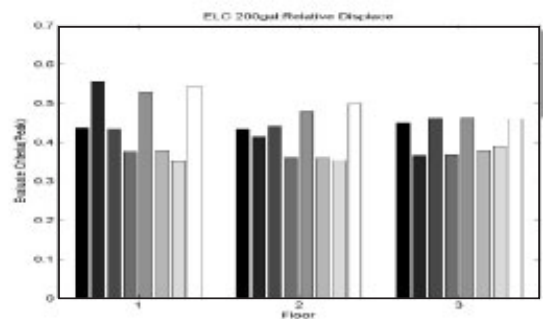

Maximum Damper Force

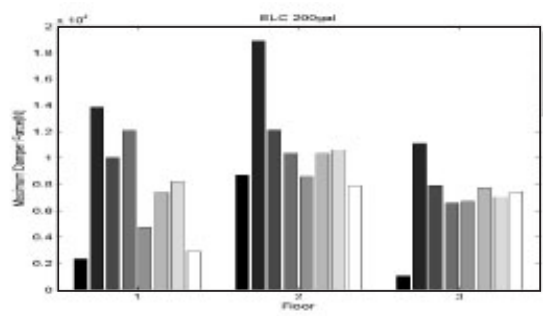

Base Shear \& Over turning Moment (Norm)

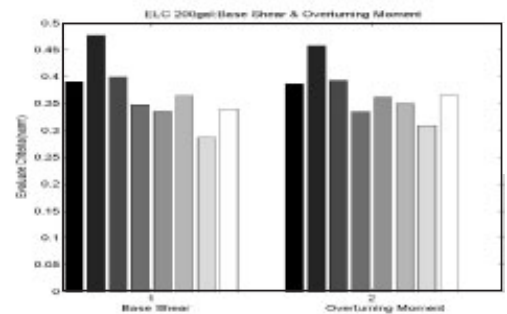

Absolute Acceleration (Norm)

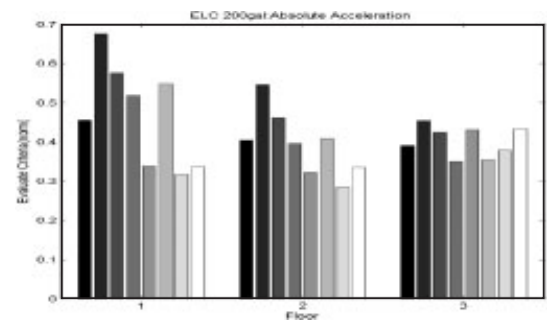

Relative Displace (Norm)

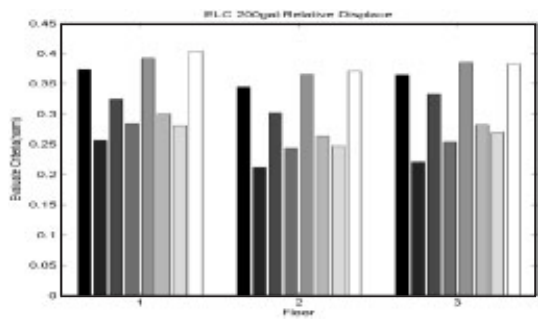

Relative Velocity (Peak)

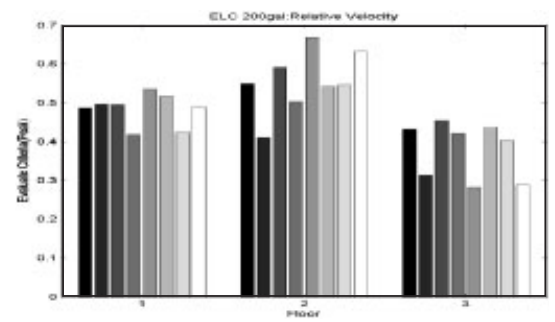

Figure 12. Comparison on structural responses between non-control system and control system with different control algorithms. 


\subsection{Validation of wireless control effectiveness}

An evaluation of MR-damper performance during experimentation is important in assessing the effectiveness of the control system. During the application of the centralized control system to the test structure, the hysteretic behaviour of each MR damper is examined. First, the centralized WiSSCon system is used to control the test structure; during a second round of testing, the NCREE control system is used implementing the same Bouc-Wen and LQG algorithms at $10 \mathrm{~Hz}$. Alternatively, the wired NCREE control system is also operated at $200 \mathrm{~Hz}$ to see if the higher sample rate impacts the hysteretic properties of the damper.

To verify the ability of the wireless control system to mitigate the dynamic response of the test structure, response time histories (acceleration and displacement) of the test structure are compared between those obtained using the wireless and wired control systems. Comparison on the floor acceleration and displacement using the wired control system $(200 \mathrm{~Hz})$ and the wireless control system $(10 \mathrm{~Hz})$ for a centralized control architecture is presented in Figure 11(a), and comparison on the floor acceleration and displacement using wireless control system between the case of centralized control $(10 \mathrm{~Hz})$ and the decentralized control $(50 \mathrm{~Hz})$ is shown in Figure 11(b). The $Q, R$ and $G$ matrices for control study is shown in Table II. The strong agreement in the mitigated time histories reveals the effectiveness of the WiSSCon system in controlling the test structure; in general, the performance of the wireless control system is on par with that of the tethered laboratory control system.

A comparison between the closed-loop feedback control and passive mitigation methods is also made. For cases of passive-on (constant $1.2 \mathrm{~V}$ supplied to the MR-damper to attain the maximum damping coefficient), passive-off (constant $0 \mathrm{~V}$ supplied to the MR-damper to attain the minimum damping coefficient), wireless $10 \mathrm{~Hz}$ centralized control, wireless $50 \mathrm{~Hz}$ decentralized control, wired $200 \mathrm{~Hz}$ centralized control and wired $200 \mathrm{~Hz}$ decentralized control, peak structural responses are recorded and compared. The results of the comparative study are presented in Figure 12. It is concluded that both centralized and decentralized controls using the wireless sensing system can reach almost the same control effectiveness as the wired control system. Furthermore, the closedloop feedback control results generally outperform those of the passive-on and passive-off cases.

\section{CONCLUSIONS}

This study examines the potential use of wireless communication and embedded computing technologies within real-time structural control applications. Based on the implementation of the prototype WiSSCon system in a three-storey steel test structure, both the centralized and decentralized control architectures are implemented to mitigate the lateral response of the test structure using MR dampers. During the test, a large earthquake time history is applied (El Centro (1940 NS) scaled to a peak acceleration of $200 \mathrm{gal}$ ) at the structure base using a shaking table. Three major performance attributes of the wireless control system were examined: (1) validation of the reliability of wireless communications for real-time applications; (2) validation of a modified Bouc-Wen damper model embedded in the wireless sensors to operate the MR dampers; and (3) exploration between the control effectiveness when using WiSSCon in a centralized and decentralized architectural configuration. The following conclusions have been drawn:

1. In this study, the WiSSCon system for structural control has been demonstrated. The performance of this novel control technology has been shown to be nearly comparable to that of 
the wired control system. Issues of stability have not been considered because of the inherent bounded input/bounded output (BIBO) nature of the semi-active control approach.

2. When applying wireless sensor networks to real-time applications, communication latency must be carefully examined. In this study, reliability of the wireless communication channel is attained by slowing the system down. Alternatively, if a sample rate greater than $10 \mathrm{~Hz}$ is desired, decentralization offers one potential solution (with an attainable sample rate of $50 \mathrm{~Hz}$ ). In the decentralized control system, only local sensor information is needed to generate the control signal sent to the MR damper. As a result, such an approach could be easily carried out for large-scale structural systems.

3. An advantage of the decentralized control approach is its robustness to failure. In other words, the approach ensures that the control system can still operate should one damper fail to operate properly. Given one sub-system fails, the other sub-systems will be capable of compensating accordingly and ensure suitable global performance of the system.

Finally, this study proves that wireless sensor networks are a promising technology capable of operating in a real-time environment. The displacement and acceleration response of the structure when using WiSSCon are nearly identical to that attained when using the wired laboratory control system. While great success has been encountered in this study, further work is needed to further refine wireless sensors for deployment in real civil structures using structural control for response mitigation. Future efforts will be focused on modification of the wireless sensor hardware to be able to attain higher sample rates consistent with the current state-of-practice $(50 \mathrm{~Hz}$ or greater). In addition, partially decentralized control architectures remain an unexplored arena for potential use in a wireless structural control system.

\section{ACKNOWLEDGEMENTS}

This research has been supported by both the National Science Council, Taiwan, under grant No. NSC 94-2625-Z-002-031 and No. NSC 95-2221-E-002-311. Additional support has been provided to Prof. J. P. Lynch (University of Michigan) by the National Science Foundation (Grant CMS-0528867) and the Office of Naval Research (Young Investigator Program). The authors would also like to express their gratitude to NCREE technicians for their assistance when conducting the shaking table experiments, and would also like to acknowledge the support and guidance offered by Prof. Kincho Law during all phases of this research endeavour.

\section{REFERENCES}

1. Straser EG, Kiremidjian AS. A modular, wireless damage monitoring system for structures. Report No. 129, John A. Blume Earthquake Engineering Research Center, Department of Civil and Environmental Engineering, Stanford University, CA, 1998.

2. Lynch JP, Sundararajan A, Law KH, Kiremidjian AS, Carryer E. Embedded damage detection algorithms in a wireless sensing unit for attainment of operational power efficiency. Smart Materials and Structures (IOP) 2004; 13(4):800-810.

3. Wang Y, Lynch LP, Law KH. Design of a low-power wireless structural monitoring system for collaborative computational algorithms. Proceedings of SPIE 10th Annual International Symposium on Nondestructive Evaluation for Health Monitoring and Diagnostics, San Diego, CA, 6-10 March 2005.

4. Lynch JP, Loh KJ, Hou TC, Wang Y, Yi J, Yun CB, Lu K, Loh CH. Validation case studies of wireless monitoring systems in civil structures. Proceedings of the 2nd International Conference on Structural Health Monitoring of Intelligent Infrastructure (SHMII-2), Shenzhen, China, November 2005; 597-604. 
5. Lynch JP, Wang Y, Lu KC, Hou TC, Loh CH. Post-seismic damage assessment of steel structures instrumented with self-interrogating wireless sensors. Proceedings of the 8th National Conference on Earthquake Engineering, San Francisco, CA, U.S.A., 18-22 April 2006.

6. Dyke SJ, Spencer BF, Sain MK, Carlson JD. Modeling and control of magnetorheological dampers for seismic response reduction. Smart Materials and Structures 1996; 5:565-575.

7. Spencer BF, Dyke SJ, Sain MK, Carlson JD. Phenomenological model for magnetorheological dampers. Journal of Engineering Mechanics (ASCE) 1997; 123:230-238.

8. Yang G, Spencer BF, Carlson JD, Sain MK. Large-scale MR fluid dampers: modeling and dynamic performance consideration. Engineering Structures 2002; 24:309-323.

9. Occhiuzzi et al. 2003.

10. Spencer BF, Nagarajaiah S. State of the art of structural control. Journal of Structural Engineering (ASCE) 2003; 129:845-856.

11. Nishitani A, Nitta Y, Ikeda Y. Semiactive structural-control based on variable slip-force level dampers. Journal of Structural Engineering (ASCE) 2003; 129(7):933-940.

12. Kurino H, Tagami J, Shimizu K, Kobori T. Switching oil damper with built-in controller for structural control. Journal of Structural Engineering (ASCE) 2003; 129(7):895-904.

13. Lin PY, Chung LL, Loh CH, Cheng CP, Roschke PN, Chang CC. Experimental study of seismic protection for structures using MR dampers. Proceedings of the 12th European Conference on Earthquake Engineering, London, September 2002; Paper no. 249.

14. Lin PY, Roschke PN, Loh CH, Cheng CP. Semi-active controlled based-isolation system with MR dampers and pendulum system. 13WCEE, Vancouver, August 2004; Paper no. 691.

15. Lynch JP, Wang Y, Swartz RA, Lu KC, Loh CH. Implementation of a closed-loop structural control system using wireless sensor networks. Journal of Structural Control and Health Monitoring 2006, submitted.

16. Doyle JC, Glover K, Khargonekar PP, Francis BA. State-space solutions to standard $\mathrm{H}_{2}$ and $\mathrm{H}_{\infty}$ control problems. IEEE Transactions on Automatic Control 1989; 34:831-847.

17. Dyke SJ, Spencer BF, Quast P, Sain MK, Kaspaari DC, Soong TT. Acceleration feedback control of MDOF structures. Journal of Engineering Mechanics (ASCE) 1996; 122(9):907-917.

18. Lin PY, Roschke P, Loh CH. System identification and real application of a smart magneto-rheological damper. Proceedings of the 2005 IEEE International Symposium on Intelligent Control, Limassol, Cyprus, 2005; 989-994. 